\title{
Prion Protein Interactome: Identifying Novel Targets in Slowly and Rapidly Progressive Forms of Alzheimer's Disease
}

\author{
Saima Zafar ${ }^{\mathrm{a}, 1, *}$, Mohsin Shafiq ${ }^{\mathrm{a}, 1}$, Neelam Younas ${ }^{\mathrm{a}}$, Matthias Schmitz ${ }^{\mathrm{a}}$, Isidre Ferrer ${ }^{\mathrm{b}, \mathrm{c}}$ \\ and Inga Zerr ${ }^{\mathrm{a}}$ \\ ${ }^{a}$ Department of Neurology, Clinical Dementia Center and DZNE, Georg-August University, \\ University Medical Center Göttingen (UMG), Göttingen, Germany \\ ${ }^{\mathrm{b}}$ Institute of Neuropathology, IDIBELL-University Hospital Bellvitge, University of Barcelona, \\ Hospitalet de Llobregat, Spain \\ ${ }^{\mathrm{c}}$ CIBERNED (Network center for biomedical research of neurodegenerative diseases), \\ Institute Carlos III, Ministry of Health, Spain
}

Accepted 4 May 2017

\begin{abstract}
Rapidly progressive Alzheimer's disease (rpAD) is a variant of AD distinguished by a rapid decline in cognition and short disease duration from onset to death. While attempts to identify rpAD based on biomarker profile classifications have been initiated, the mechanisms which contribute to the rapid decline and prion mimicking heterogeneity in clinical signs are still largely unknown. In this study, we characterized prion protein (PrP) expression, localization, and interactome in rpAD, slow progressive $\mathrm{AD}$, and in non-dementia controls. PrP along with its interacting proteins were affinity purified with magnetic Dynabeads Protein-G, and were identified using Q-TOF-ESI/MS analysis. Our data demonstrated a significant 1.2-fold decrease in di-glycosylated PrP isoforms specifically in rpAD patients. Fifteen proteins appeared to interact with PrP and only two proteins3/4histone H2B-type1-B and zinc alpha-2 protein3/4were specifically bound with PrP isoform isolated from rpAD cases. Our data suggest distinct PrP involvement in association with the altered PrP interacting protein in rpAD, though the pathophysiological significance of these interactions remains to be established.
\end{abstract}

Keywords: Aldolase A, Alzheimer's disease, co-immunofluorescence, co-immunoprecipitation, histone, myelin P2, peroxiredoxin 1 , prion, proteomics, synapsin, tubulin, zinc

\section{INTRODUCTION}

Alzheimer's disease (AD) is a common form of dementia affecting more than 37 million people worldwide $[1,2]$. The prevalence of slow progressive AD (spAD) pathology is well studied [3, 4], however, a subset of rapidly progressive $\mathrm{AD}$ (rpAD)

\footnotetext{
${ }^{1}$ These authors contributed equally to this work.

*Correspondence to: Dr. Saima Zafar, Department of Neurology, Clinical Dementia Center and DZNE, University Medical Centre Göttingen, 37075, Göttingen, Germany. Tel.: +49 551 39 14962; E-mails: sz_awaan@yahoo.com; saima.zafar@med.unigoettingen.de.
}

cases mimicking prion diseases is emerging [5-9]. These rpAD cases show distinct clinical parameters $[5,6,9]$ and pathological features [10], though the risk factors and pathological mechanisms leading to heterogeneous progression rates and phenotypes of $\mathrm{AD}$ are still not known [3].

In recent years, neuropathological similarities, genetic acquaintances, and coexistence between $\mathrm{AD}$ pathology and prion diseases have been reported [11]. Some studies report coexistence between prion protein $(\mathrm{PrP})$ and amyloid- $\beta(\mathrm{A} \beta)$ in plaques $[12,13]$. A genetic correlation and systematic meta-analysis shows PRNP to be a gene potentially related to 
AD susceptibility [14] with Met/Val 129 polymorphism as a potential risk factor for early onset of $\mathrm{AD}[13,15,16]$. Interestingly, the cellular form of PrP also appears to be a high-affinity receptor for $A \beta$ oligomers [17-19], and a population of soluble oligomers $(\mathrm{A} \beta \mathrm{O})$ was found to interact with $\operatorname{PrP}$ in $\mathrm{AD}$ and cause behavioral impairment. The coherence between the levels of $A \beta o$ interacting with PrP appears to have significance importance in $\mathrm{AD}$ progression and $\mathrm{PrP}$ plays a pivotal role in AD pathobiology [20]. Despite the fact that such pathological and genetic links between $\mathrm{AD}$ and PrP have been identified, there is no evidence of a world-wide PrP-interacting risk factor involved in the course of a slow or a rapid progression of the disease.

In this study, we demonstrate that posttranslationally modified PrP isoforms are reduced specifically in rpAD patients, and that PrP-interacting risk factors may be involved in the slow or rapid progression of $\mathrm{AD}$ pathology.

\section{MATERIALS AND METHODS}

The brain samples were provided by the Prion Disease Surveillance Units of Germany and Spain including, i.e., spAD, rpAD, sporadic Creutzfeldt-Jakob disease (sCJD), and nondemented control cohorts as described previously [8]. Human samples from Spain were obtained following the Spanish legislation (Ley de la Investigación Biomédica 2013 and Real DecretoBiobancos, 2014) and the approval of the local ethics committees. All experimental protocols were approved and the study conformed to the Code of Ethics of the World Medical Association. All study participants or their legal next of kin gave informed consent and the study was approved by the local ethics committee in Göttingen (No. 24/8/12). All samples were anonymized with regard to at personal data and are summarized in Table 1).

Brain tissue samples were processed as demonstrated previously $[8,21]$. Briefly, frontal cortex area 28 was taken from $\mathrm{spAD}$ cases $(8 \mathrm{M} / 5 \mathrm{~F})$ with mean age of 75 years, rpAD cases $(5 \mathrm{M} / 4 \mathrm{~F})$ with mean age of 69 years, and age-matched non-demented controls $(8 \mathrm{M} / 2 \mathrm{~F})$. Sucrose velocity gradient ultracentrifugation was performed as described previously with slight modification [7]. Briefly, samples were homogenized by $10 \% \mathrm{w} / \mathrm{v}$ of tissue in $1 \mathrm{x}$ PBS containing $2 \%$ w/v sarkosyl ( $\mathrm{pH}$ 7.4). Homogenates were layered onto the top of $10-45 \%$ sucrose continuous gradients. Ultracentrifugation was performed at $50,000 \mathrm{rpm}$ for $73 \mathrm{~min}$ at $5^{\circ} \mathrm{C}$ and 20 fractions were collected from top to bottom.

Frozen and paraffin-embedded tissue sections were processed and immunofluorescence and confocal laser scanning microscopy was performed as described previously $[8,22]$. Anti-PrP 3F4 (1:200), anti-PrP SAF70 (1:250), anti- ZAG $(1: 100)$, Alexa 488/546 conjugated anti-rabbit $(1: 200)$, and TO-PRO-3 iodide were used. Tissue lysis, immunoblotting co-immunoprecipitation were performed as described previously [8].

Furthermore, we performed in-gel tryptic digestion leading to peptide sequence analysis. Briefly, specific bands were excised from silver-stained 1DE gel into $1-2 \mathrm{~mm}^{2}$ slices. Slices were then washed in $\mathrm{ddH}_{2} \mathrm{O}$, reduced with $10 \mathrm{mM}$ dithiothreitol by incubating for $30 \mathrm{~min}$ at $56^{\circ} \mathrm{C}$, and alkylated with $55 \mathrm{mM}$ idoacetamide at room temperature in dark for $60 \mathrm{~min}$. Gel slices were then washed in acetonitrile (ACN) for $15 \mathrm{~min}$ and dried in a SpeedVac to remove excess solvent. Protease cleavage was done by rehydrating dried gel slices with the minimum amount of porcine trypsin solution $(12.5 \mathrm{ng} / \mu \mathrm{l}$ in $0.025 \mathrm{M}$ aqueous ammonium bicarbonate) for overnight at $37^{\circ} \mathrm{C}$. After tryptic digestion, gel slices

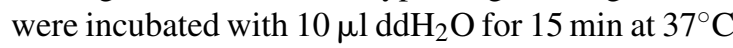
followed by addition of $80 \mu \mathrm{l}$ ACN and incubation for $15 \mathrm{~min}$ at $37^{\circ} \mathrm{C}$. Supernatant was taken after a short spin. Residual peptides were dissolved from gel slices by vortex and incubation in $65 \mu \mathrm{l} 5 \%$ formic acid for $15 \mathrm{~min}$ at $37^{\circ} \mathrm{C}$. ACN $65 \mu \mathrm{l}$ was added and further incubated for $15 \mathrm{~min}$ at $37^{\circ} \mathrm{C}$. Supernatant was collected after a short spin and added to supernatant from the previous step. Combined supernatant was evaporated to dryness in a vacuum concentrator. Dried samples were dissolved in $10 \mu \mathrm{l}$ of $30 \% \mathrm{ACN}$ and $0.1 \%$ triflouroacetic acid.

For mass spectrometric analysis, peptide mixtures were concentrated on a Reversed Phase-C18 precolumn $(0.15 \mathrm{~mm}$ ID $\times 20 \mathrm{~mm}$, self-packed with Reprosil-Pur 120 C18-AQ $3 \mu \mathrm{m}$ material) followed by separation using Reversed Phase-C18 nanoflow chromatography (Picofrit column, 0.07 $5 \mathrm{~mm}$ ID $\times 200 \mathrm{~mm}$ (New Objective, Woburn, USA)) using a 15 min linear gradient on an Easy nLC-1000 nanoflow chromatography system (Thermo Fisher Scientific, Dreieich, Germany). Eluents were analyzed on a Q Exactive hybrid quadrupole/orbitrap mass spectrometry system operated under Excalibur 
Table 1

Patient details: Summary of cases used in the present study

\begin{tabular}{|c|c|c|c|c|c|c|}
\hline No. & Patient ID & Gender & Age & $\begin{array}{c}\text { Disease } \\
\text { duration (y) }\end{array}$ & $\begin{array}{c}\text { Braak } \\
\text { stages (AD) }\end{array}$ & $\begin{array}{l}\text { Postmortem } \\
\text { delays (h) }\end{array}$ \\
\hline 1 & rpAD1 & Male & 70 & $<4$ & $\mathrm{VI} / \mathrm{C}$ & $11: 30$ \\
\hline 2 & rpAD2 & Male & 76 & $<4$ & $\mathrm{VI} / \mathrm{C}$ & $06: 30$ \\
\hline 3 & rpAD3 & Female & 76 & $<4$ & $\mathrm{VI} / \mathrm{C}$ & $18: 00$ \\
\hline 4 & rpAD4 & Female & 77 & $<4$ & IV/A & $12: 00$ \\
\hline 5 & rpAD5 & Male & 78 & $<4$ & $\mathrm{~V} / \mathrm{C}$ & $03: 30$ \\
\hline 6 & rpAD6 & Female & 79 & $<4$ & $\mathrm{~V}$ & $05: 30$ \\
\hline 7 & rpAD7 & Female & 81 & $<4$ & III/B & $06: 00$ \\
\hline 8 & rpAD8 & Male & 83 & $<4$ & $\mathrm{VI} / \mathrm{C}$ & $05: 30$ \\
\hline 9 & rpAD9 & Male & 83 & $<4$ & $\mathrm{~V} / \mathrm{C}$ & $08: 20$ \\
\hline 10 & spAD1 & Female & 56 & $>4$ & $\mathrm{~V} / \mathrm{C}$ & $07: 00$ \\
\hline 11 & spAD2 & Male & 64 & $>4$ & II/A & $06: 00$ \\
\hline 12 & spAD3 & Female & 67 & $>4$ & $\mathrm{III} / \mathrm{C}$ & $06: 10$ \\
\hline 13 & spAD4 & Male & 69 & $>4$ & $\mathrm{III} / 0$ & $13: 10$ \\
\hline 14 & spAD5 & Female & 71 & $>4$ & $\mathrm{III} / 0$ & $07: 15$ \\
\hline 15 & spAD6 & Female & 72 & $>4$ & $\mathrm{~V} / \mathrm{C}$ & $09: 30$ \\
\hline 16 & spAD7 & Female & 75 & $>4$ & $\mathrm{~V} / \mathrm{C}$ & $04: 15$ \\
\hline 17 & spAD8 & Male & 78 & $>4$ & $\mathrm{~V} / \mathrm{C}$ & $09: 30$ \\
\hline 18 & spAD9 & Female & 82 & $>4$ & $\mathrm{VI} / \mathrm{B}$ & $01: 45$ \\
\hline 19 & spAD10 & Male & 83 & $>4$ & $\mathrm{III} / 0$ & $07: 25$ \\
\hline 20 & spAD11 & Male & 87 & $>4$ & $\mathrm{~V} / \mathrm{C}$ & $07: 05$ \\
\hline 21 & spAD12 & Female & 90 & $>4$ & IV/A & $09: 55$ \\
\hline 22 & spAD13 & Female & 93 & $>4$ & $\mathrm{~V} / \mathrm{C}$ & $03: 00$ \\
\hline 23 & sCJD 1 & Female & 72 & $<1$ & - & $06: 00$ \\
\hline 24 & sCJD 2 & Male & 79 & $<1$ & - & $09: 45$ \\
\hline 25 & sCJD 3 & Female & 60 & $<1$ & - & $07: 50$ \\
\hline 26 & sCJD 4 & Male & 46 & $<1$ & - & $07: 00$ \\
\hline 27 & sCJD 5 & Female & 65 & $<1$ & - & $05: 05$ \\
\hline 28 & sCJD 6 & Male & 83 & $<1$ & - & $11: 00$ \\
\hline 29 & sCJD 7 & Male & 76 & $<1$ & - & $04: 50$ \\
\hline 30 & sCJD 8 & Male & 64 & $<1$ & - & $11: 30$ \\
\hline 31 & Cont 1 & Male & 69 & - & II/A & $05: 03$ \\
\hline 32 & Cont 2 & Male & 68 & - & $\mathrm{I} / 0$ & $05: 03$ \\
\hline 33 & Cont 3 & Female & 64 & - & $\mathrm{I} / 0$ & 09:00 \\
\hline 34 & Cont 4 & Male & 67 & - & $\mathrm{I} / 0$ & $05: 03$ \\
\hline 35 & Cont 5 & Male & 74 & - & II/A & $11: 00$ \\
\hline 36 & Cont 6 & Male & 86 & - & II/A & $06: 45$ \\
\hline 37 & Cont 7 & Female & 73 & - & $\mathrm{I} / 0$ & $04: 03$ \\
\hline 38 & Cont 8 & Male & 70 & - & I/A & $09: 00$ \\
\hline 39 & Cont 9 & Male & 61 & - & $\mathrm{I} / 0$ & $03: 03$ \\
\hline 40 & Cont 10 & Male & 77 & - & $\mathrm{I} / \mathrm{A}$ & $11: 00$ \\
\hline
\end{tabular}

Disease duration less than four years $(<4)$ consider as rapid forms and more than four year $(>4)$ considered as slow forms of $\mathrm{AD}$. rpAD, rapid progressive Alzheimer's disease; spAD, slow progressive classical Alzheimer's disease; sCJD, Creutzfeldt-Jakob disease; Cont, control (non-demented).

v2.4 software (Thermo Fisher Scientific). Analysis was carried by a Top10 method in the Data Dependent Acquisition mode. Tandem mass spectra were extracted for database searching, using Raw2MSM v1.17 software (Max Planck Institute for Biochemistry, Martinsried, Germany). MS/MS samples were analyzed using Mascot (Matrix Science, London, UK; version 2.4.1) set for searching UniProt/SwissProt database (release 02/14 filtered for Homo sapiens entries) with $5 \mathrm{ppm}$ mass tolerances for precursors and $0.020 \mathrm{Da}$ for fragments, respec- tively. Methionine oxidation was used as a variable modification and cysteine carbamidomethylation as a fixed modification. Up to two missed cleavages were allowed. Scaffold software v4.4.1.1 (Proteome Software, Portland/OR, USA) was used for validation of MS/MS based peptide and protein identifications. Peptide identifications were accepted, if established at greater than $95.0 \%$ confidence. While, a minimum of two confident peptide identifications and a confidence threshold of $99.0 \%$ were required for protein identifications [23]. 
A.
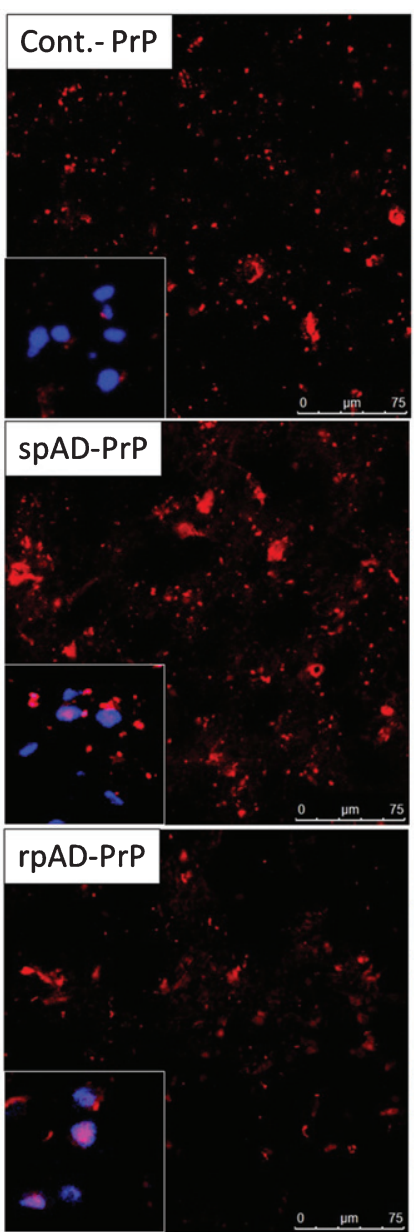
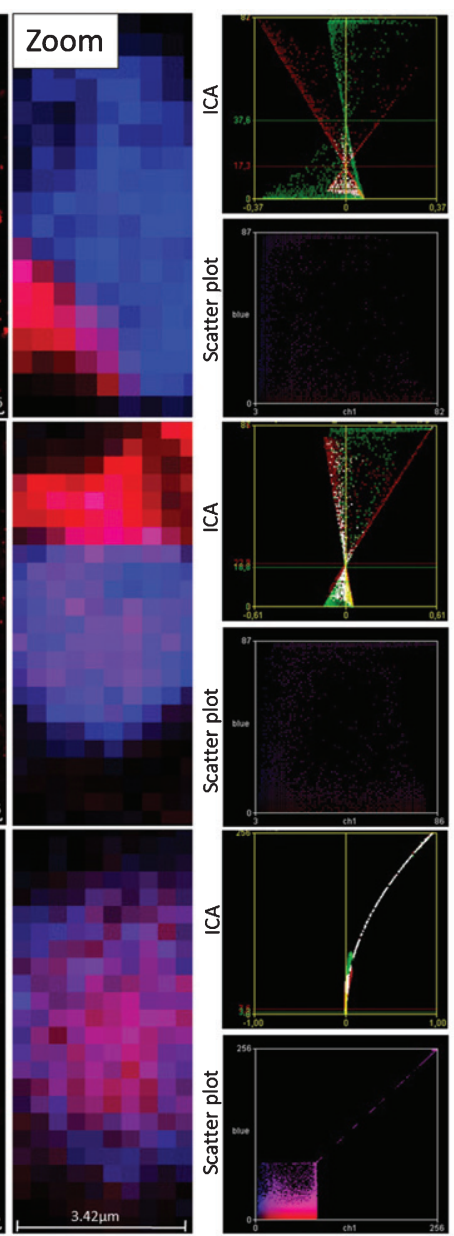

B.

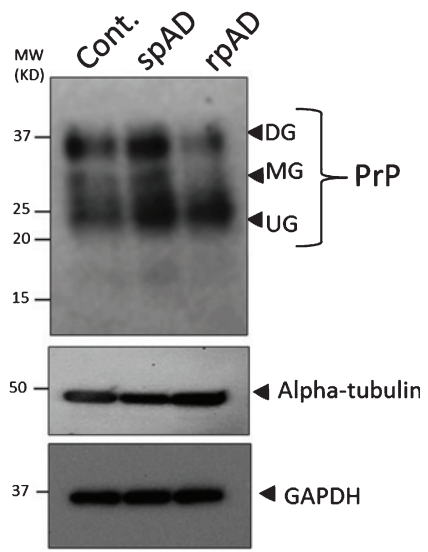

C.

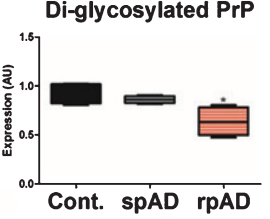

D. Mono-glycosylated PrP

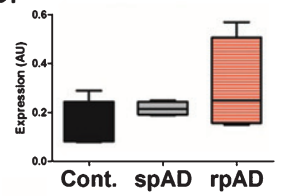

E. Un-glycosylated PrP

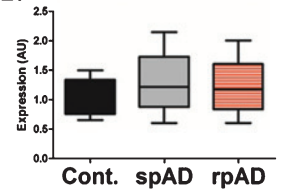

F.

Cont.-PrP

SpAD-PrP

rpAD-PrP

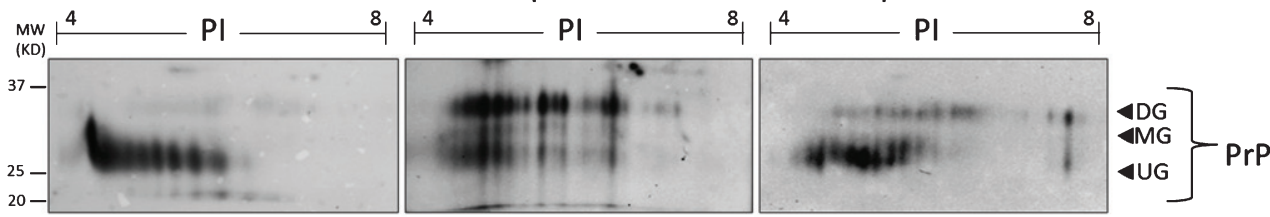

Colocalization + FRET index
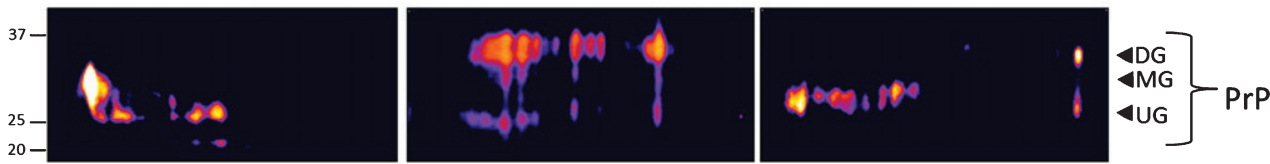

Fig. 1. Characteristically distinct PrP isoforms in spAD and rpAD human brains. A) Localization of PrP and nuclear immunoreactivity in the frontal cortex brain region in SpAD, rpAD, and control brain tissues using SAF70 anti-PrP antibody. Zoom shows overlapping of nucleus with PrP. ICA and scatter plots illustrate the colocalization pixel intensities between PrP and nucleus. B) PrP expression in spAD and rpAD by using SAF70 anti-PrP antibody and immunoblotting analysis and beta actin as loading control. DG, di-glycosylated isoforms; MG, mono-glycosylated isoforms; UG, un-glycosylated isoforms. C-E) Densitometry analysis from four independent ( \pm SD) immunoblotting experiments using 15 controls (Con), $15 \mathrm{spAD}$, and $8 \mathrm{rpAD}$ cases. F) Immunoblots from 2-DE gels of controls, spAD and rpAD proteins, using SAF70 anti-PrP antibody. Linear $7 \mathrm{~cm}$ IPG strips ( $\mathrm{pH} 4-8)$ were used and loaded with $50 \mu \mathrm{g}$ of protein. Upper panels represent colocalization points (ImageJ WCIF plugin) and lower panel represents co-localization and FRET index (ImageJ FRET plugin) of silver-stained 2-DE gels in spAD, rpAD, and controls. Pearson's co-localization correlation co-efficient $\mathrm{rp}(-1 \leq \mathrm{rp} \leq 1)$ experiments and FRET index were generated by ImageJ (WCIF plugin) software. The significance was calculated with the one-way ANOVA Friedman test $\left({ }^{*} p<0.05\right)$ and AU arbitrary units. 
A.

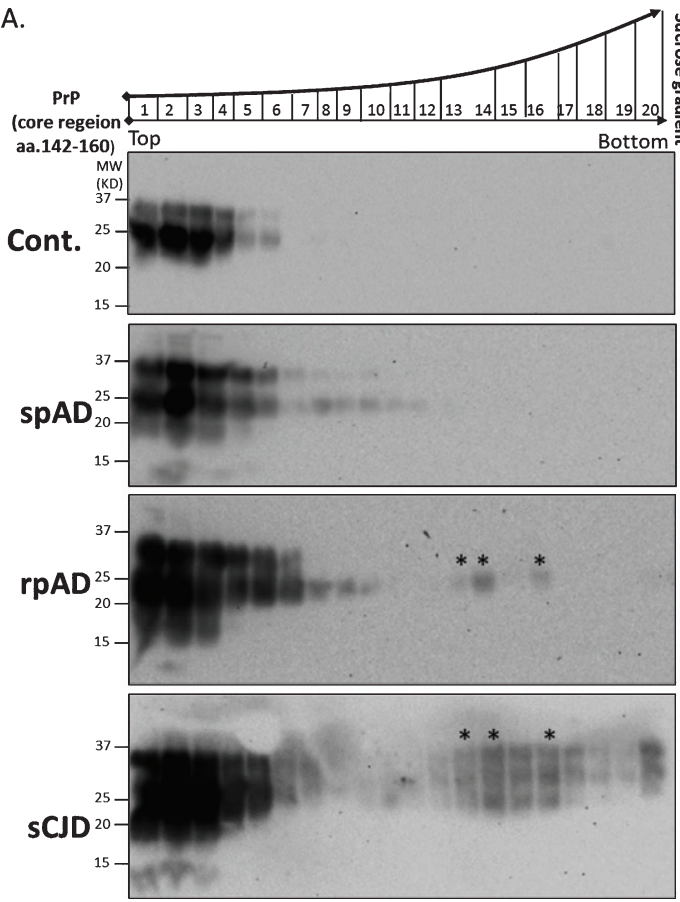

B.

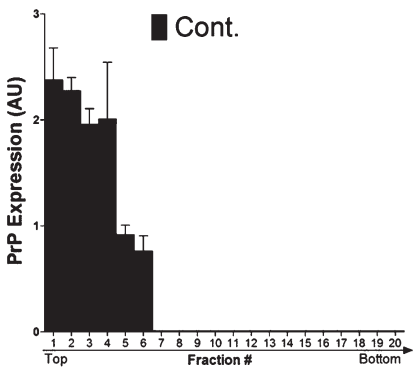

D.

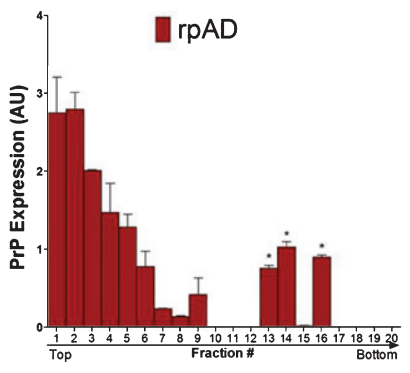

C.

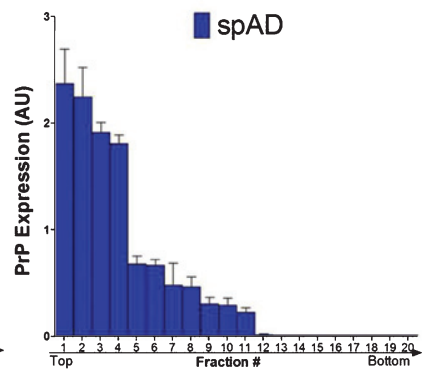

E.

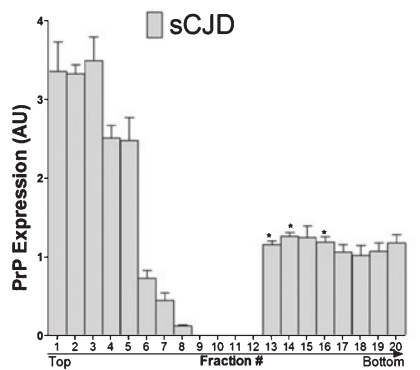

Fig. 2. Separation of characteristically distinct PrP isoforms by sedimentation velocity in sucrose gradient in spAD and rpAD human brains. A) Separation of PrP isoforms by sedimentation velocity in sucrose gradient. The gradient fractionation profile of PrP particles from spAD, $\mathrm{rpAD}, \mathrm{SCJD}$, and controls after separation by ultracentrifugation in sucrose gradient. Fractions collected from the bottom of the tubes were immunoblotted by anti-PrP mAb SAF70. B-E) Densitometry analysis from four independent $( \pm$ SD) immunoblotting experiments in 15 controls (Con), $15 \mathrm{spAD}, 8 \mathrm{rpAD}$ cases, $15 \mathrm{sCJD}$, and 15 non-demented controls and graph was generated by Prism 5 software. The significance was calculated with the one-way ANOVA Friedman test $\left({ }^{*} p<0.05\right)$ and AU arbitrary units.

\section{RESULTS}

\section{Characteristic and distinct PrP isoforms in spAD and rpAD human brains}

The distinct PrP isoforms and aberrant localization of PrP in spAD and rpAD brain may be characterized by different phenotypes and binding domains or the interplay of specific mechanisms during the disease progression.

In this study, we found differential PrP immunoreactivity in the neuronal cell bodies of the frontal cortex region of spAD brains, rpAD, and control brain tissues. PrP expression was significantly increased in spAD and rpAD cases as compared to controls. rpAD cases also showed significantly weaker immunoreactivity as compared to spAD cases (Fig. 1A). Notably, PrP showed aberrant localization toward the nuclear region specifically in $\mathrm{rpAD}$ as compared to age-matched controls (Fig. 1A). The differential expression of PrP by one- and twodimensional immunoblot reveals a 1.2-fold $(p \leq 0.05)$ decrease in $\mathrm{rpAD}$ as compared to the characteristic isoforms of PrP in the post-translationally modified di-glycosylated PrP isoforms (Fig. 1B-F). Colocalization and the FRET index suggest that the rpAD cases showed the significant decrease of PrP isoforms at the size of $37 \mathrm{kDa}$ (Fig. 1F).

To further characterize the hydrodynamic information on the size and shape of PrP molecules in rpAD as compared to spAD and controls, we used a high-speed ultra-centrifugation and sucrose gradient to evaluate the sedimentation velocity. We also used SCJD cases as PrP controls in this sedimentation assay to check for a possible overlap of PrP isoforms between rpAD and CJD cases. The PrP in the brain tissue of controls, spAD, rpAD, and sCJD cases remained in the top (1-6) fractions, as expected for monomers or dimers of $\operatorname{PrP}$ (Fig. 2). However, a broad range of densities and a variable fraction (7-12) remained floating in spAD and rpAD cases (Fig. 2C, D). Interestingly, rpAD showed a distinct species of PrP in the fraction $(13,14$, and 16), similar to SCJD cases (Fig. 2A, D, E). However, these fractions in 
A.

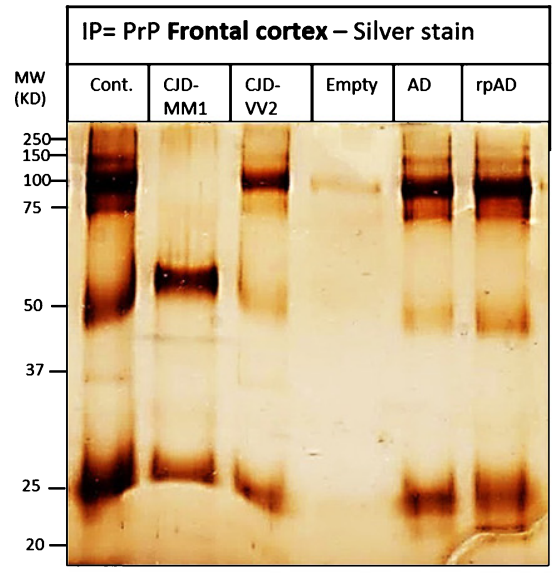

C.

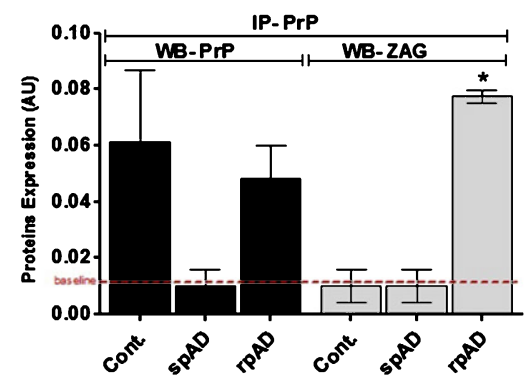

D.

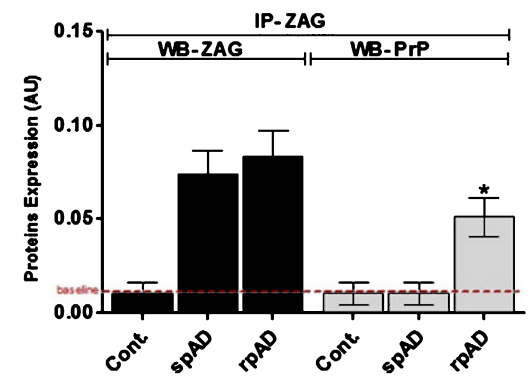

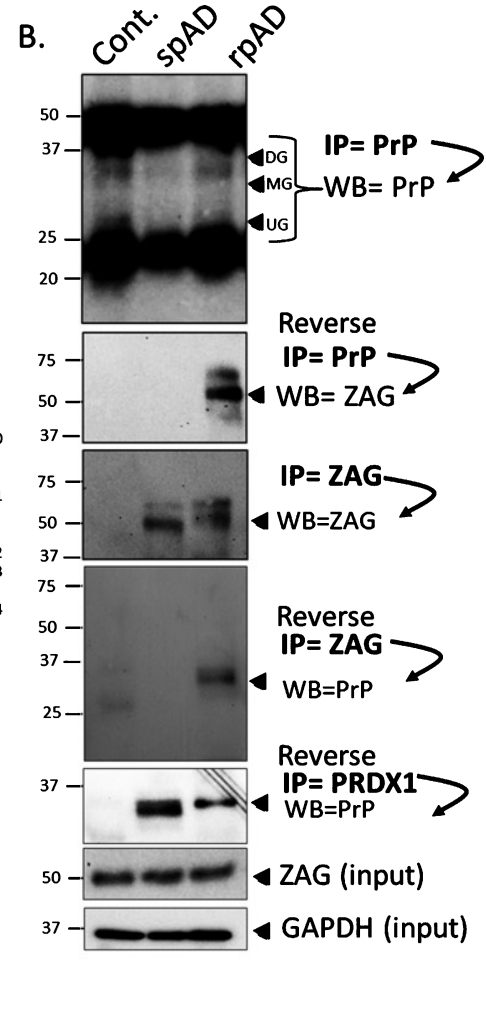

E. ZAG
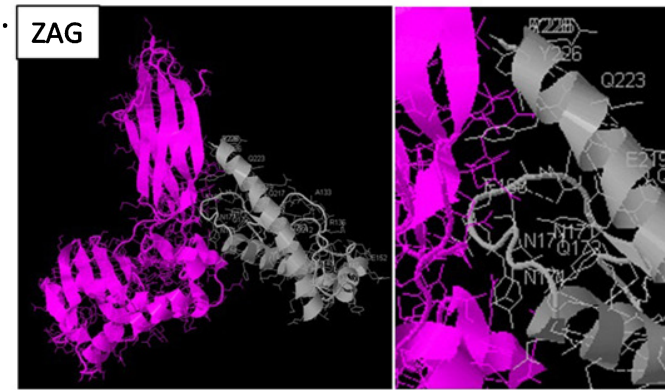

F. PrP/ZAG/Nucleus
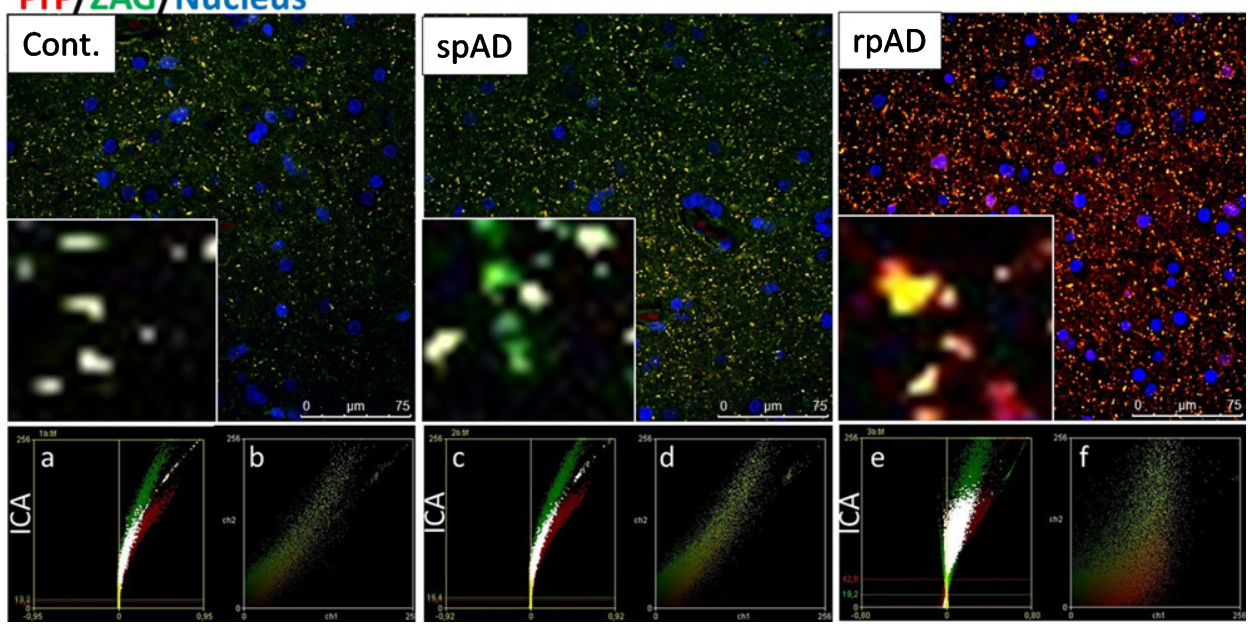
rpAD were not proteinase K-resistant as compared to SCJD (data not shown here).

\section{Characteristic PrP interactome identification in $s p A D$ and $r p A D$ human brains}

We isolated PrP-interacting partners from spAD, rpAD, and controls by co-purification of PrP, using Protein $\mathrm{G}$ coupled to super magnetic Dynabeads ${ }^{\circledR}$ (Fig. 3A). Eluates from this co-immunoprecipitation with SAF32 and SAF70 PrP were stained silver (Fig. 3A) and whole lanes from spAD, rpAD, and control eluate were excised and recovered with tryptic in-gel/in-solution digestion. Proteins were identified with ESI/Q-TOF MS/MS. Both known and novel PrP-interacting partners were among the proteins identified in this study (Table 2). The ESI/Q-TOF MS/MS identified proteins based on protein identification probability, the exclusive unique peptide count, and total spectrum count; the spectrum and sequence are summarized in Supplementary Table 1 listing fifteen proteins as interacting partners of PrP. Of these fifteen proteins, two-histone H2B type 1B (H2B-1B) and zinc alpha-2 protein (ZAG) - were specifically bound with PrP isolated from rpAD cases. Furthermore, three proteins, i.e., tubulin beta 2C, synaptojanin-1, and synaptopodin, showed no potential interaction with the PrP isoform from spAD and rpAD cases, and appeared to bind with controls. Interestingly, one protein, myelin P2, was alone isolated as the binding partner with the PrP isoform in $\mathrm{AD}$ samples. Four interacting proteins, i.e., peroxiredoxin-1, four-and-half LIM domains protein 1 , transketolase variant (fragment), and the basic myelin protein, were commonly found in $\mathrm{AD}$ and $\mathrm{rpAD}$ cases. Four interacting proteins, namely ribonuclease UK114, fructose-bisphosphate aldolase $\mathrm{A}$ and lysozyme $\mathrm{C}$, were found in common in $\mathrm{AD}$ and non-demented healthy controls; and lastly, synapsin1 and myelin proteolipid proteins were found to interact with PrP in all cases.
ZAG and PRDX1 were further validated by immunoblotting after reverse and co-immunoprecipitation. We used ZAG and PRDX1 proteins as bait protein under non-denaturing conditions and were able to isolate (prey) PrP protein only in rpAD brain samples from specifically ZAG-binding complex (Fig. 3B-D). This immunoprecipitation and reverse co-immunoprecipitation were performed under physiological conditions and proteins were post-translationally modified and conformationally natural. Additionally, we used PrDX1 as bait and managed to isolate $\operatorname{PrP}$ from both $\mathrm{AD}$ disease subtypes (spAD and rpAD). Isolated $\operatorname{PrP}$ and immunoblotting showed no signal from control brain samples (Fig. 3B).

Furthermore, we performed co-localization analysis by using confocal laser scanning microscopy and demonstrated that ZAG specifically and significantly showed increased co-localization with PrP in rpAD in the cortex region of the brain in contrast to spAD and controls groups (Fig. 3F). Use of ICA and scatter plots highlight the interaction between $\operatorname{PrP}$ and ZAG in rpAD brain samples (Fig. 3F a-f). We could also predict the molecular interactions by using the computational protein docking program ZDOCK to look for possible interaction sites between PrP and ZAG, which we indeed found (Fig. 3E).

\section{DISCUSSION}

The emerging field of proteomics and proteinprotein interaction complexes can provide important insights into disease mechanisms. Recent studies using genome-wide protein expression by microarrays successfully predicted the disease outcome of a patient by correlating human interactome data [24].

In this study, we were able to successfully isolate PrP-interacting proteins from patients with heterogeneous $\mathrm{AD}$ during disease progression. This study clearly demonstrates a differential expression and

Fig. 3. Characteristic PrP interactome identification in spAD and rpAD human brains. PrP-interacting partners isolated from spAD, rpAD, and control cases by using SAF32 and SAF70 PrP Protein G coupled to super magnetic Dynabeads. The bands were excised, in-gel digested, and proteins were identified by ESI/Q-TOF MS/MS analysis. A) IP eluates were stained silver, illustrating the PrP-interacting proteins in spAD, rpAD, and controls. B) IP eluates were immunoblotted against PrP and ZAG by using specific monoclonal antibodies. ZAG and GAPDH immunoblotting analysis in spAD, rpAD, and control samples were used as loading controls. C, D) Densitometry analysis from four independent $( \pm \mathrm{SD})$ IP eluates immunoblotting experiments with 15 controls $(\mathrm{Con}), 15 \mathrm{spAD}$, and 8 rpAD cases each. The significance was calculated with the one-way ANOVA Friedman test $\left({ }^{*} p<0.05\right)$ and AU arbitrary units. E) Bioinformatic protein-protein prediction shows PrP (grey) and ZAG (pink) interacting sites by ZDOCK 3.0, and the molecule represents its corresponding centered orientation. F) Co-localization of PrP and ZAG in the frontal cortex brain region of spAD, rpAD, and control brain tissues using SAF70 anti-PrP antibody (red signal) and ZAG antibody (green signal). Zoom shows overlapping (yellow signal) of PrP and ZAG in the frontal cortex brain region of spAD, rpAD, and control brains. ICA (a, c, e) and scatter plots (b, d, f) illustrate the interaction between PrP and ZAG in rpAD brain samples. 
Table 2

List of prion protein interacting proteins in $\mathrm{rpAD}$ and spAD by using ESI/MS analysis

\begin{tabular}{|c|c|c|c|c|c|c|c|}
\hline \multicolumn{2}{|c|}{ No. Protein Name } & \multirow{2}{*}{$\begin{array}{l}\text { Disease } \\
\text { Specific } \\
\text { rpAD }\end{array}$} & \multirow{2}{*}{ 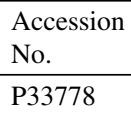 } & \multirow{2}{*}{$\begin{array}{l}\text { Localization } \\
\text { (UniProt) } \\
\mathrm{Nu}\end{array}$} & \multirow{2}{*}{$\begin{array}{l}\begin{array}{l}\text { Relevance } \\
(\mathrm{AD})\end{array} \\
\text { Known [26] }\end{array}$} & \multirow{2}{*}{$\begin{array}{l}\begin{array}{l}\text { Relevance } \\
\text { (Prion) }\end{array} \\
\text { Known [30] }\end{array}$} & \multirow{2}{*}{$\begin{array}{l}\text { PrP ligand } \\
\text { Novel }\end{array}$} \\
\hline 1 & Histone H2B type 1-B & & & & & & \\
\hline 2 & Zinc alpha-2 protein & $\mathrm{rpAD}$ & P25311 & $\mathrm{Nu}, \mathrm{Pm}, \mathrm{Ee}$ & Known [31] & Novel & Novel \\
\hline 3 & Peroxiredoxin-1 & $\mathrm{rpAD}$ and $\mathrm{AD}$ & Q06830 & $\mathrm{Nu}, \mathrm{C}, \mathrm{Ee}$ & Known [32-37] & Known $[28,38]$ & Known $[28$ \\
\hline 4 & Four and a half LIM domains protein 1 & $\mathrm{rpAD}$ and $\mathrm{AD}$ & Q13642 & $\mathrm{C}, \mathrm{Nu}, \mathrm{Pm}, \mathrm{Fa}$ & Known [43] & Known [43] & Known $[44$ \\
\hline 5 & Transketolase variant (Fragment) & $\mathrm{rpAD}$ and $\mathrm{AD}$ & Q53EM5 & - & Known [45-49] & Known [50] & Novel \\
\hline 6 & Myelin basic protein & rpAD and $A D$ & P02686 & $\mathrm{Mm}, \mathrm{Cs}$ & Known $[39,51-54]$ & Known $[55,56]$ & Novel \\
\hline 7 & Myelin P2 & $\mathrm{AD}$ & P02689 & $\mathrm{C}, \mathrm{Ee}, \mathrm{Ms}$ & Known $[57,58]$ & Known [59] & Novel \\
\hline 8 & Tubulin, beta $2 \mathrm{C}$ & Cont & Q8IZ29 & $\mathrm{C}$ & Known $[60,61]$ & Known $[28,62]$ & Known $[28$ \\
\hline 9 & Synaptojanin -1 & Cont & O43426 & $\mathrm{C}, \mathrm{Cp}$ & Known [63-66] & Known [67] & Novel \\
\hline 10 & Synaptopodin & Cont. & Q8N3V7 & $\mathrm{C}, \mathrm{Ck}, \mathrm{Cj}$ & Known [68-70] & Novel & Novel \\
\hline 11 & Ribonuclease UK114 & $\mathrm{AD}$ and Cont & P52758 & $\mathrm{C}, \mathrm{Nu}$ & Known [71] & Known [72] & Novel \\
\hline 12 & Fructose-bisphosphate aldolase A & $\mathrm{AD}$ and Cont & P04075 & $\mathrm{C}$ & Known $[37,61]$ & Known $[28,73-75]$ & Known \\
\hline 13 & Lysozyme C & $\mathrm{AD}$ and Cont & P61626 & $\mathrm{S}, \mathrm{Ee}$ & Known [76] & Known [77] & Novel \\
\hline 14 & Synapsin-1 & all & P17600 & $\mathrm{Cj}, \mathrm{Ga}, \mathrm{Sv}$ & Known [68-70] & Known [78-80] & Known $[81$ \\
\hline 15 & Myelin Proteolipid protein & all & P60201 & Ms, Pm & Known [39-41] & Novel & Known $[42$ \\
\hline
\end{tabular}

rpAD, rapid progressive Alzheimer's disease; AD, slow progressive classical Alzheimer's disease; Cont, control (non-demented); Nu, nucleus; Pm, plasma membrane; Ee, extracellular exosome; C, cytoplasm; Ms, myelin sheath; Fa, focal adhesion; Mm, myelin membrane; $\mathrm{Cs}$, cytoplasmic side; $\mathrm{Cm}$, cell membrane; $\mathrm{Cp}$, clathrin coat of coated pit; $\mathrm{Cj}$, cell junction, $\mathrm{Ck}$, cytoskeleton; $\mathrm{S}$, secreted; Ga, Golgi apparatus; Sv, synaptic vesicle.

The localization of proteins and accession number is assigned as in ExPASy protein database and Uniprot data base. Relevance with AD, prion and PrP ligand were established by deep NCBI literature database search. Tandem mass spectra were extracted and all samples were analyzed using Mascot (Matrix Science, London, UK; version 2.3.02). Mascot was set up to search the uniprot_human_database and used trypsin enzyme for protein digestion. Mascot was searched with a fragment ion mass tolerance of $0.60 \mathrm{Da}$ and a parent ion tolerance of 10.0 PPM. Methyl of lysine and arginine, oxidation of Methionine, dimethyl of lysine and arginine, acetyl of lysine, trimethyl of lysine were specified as variable modifications, whereas carbamidomethyl of cysteine was specified as fixed modification in Mascot database search. For protein identification Scaffold (version Scaffold_4.4.7, Proteome Software Inc., Portland, OR) was used to validate MS/MS based peptide and protein identifications. Peptide identifications were accepted if probability by the Peptide Prophet algorithm showed greater than $96.0 \%$ [31], greater than $95.0 \%$ probability and at least 2 identified peptides.

localization of PrP in the rpAD brain as compared to the brains of spAD patients.

In spAD and $\mathrm{rpAD}$ cases, the differences in PrP expression, localization, and particle size may influence tissue-specific complexes and their associated cellular signaling pathways. Lately it has also been demonstrated that PrP binds with $A \beta$ in $\mathrm{AD}$ patients, and exosomal PrP neutralizes the neurotoxicity caused by $A \beta$ through the fibrillization mechanism $[19,25]$. We were able to isolate PrP-interacting protein complexes, demonstrating a number of novel interacting proteins involved in AD pathology. We also identified several proteins already known to contribute to the disease pathology, which confirms the validity of our data. Other novel proteins were identified with a disease-specific contribution.

Interestingly, two proteins-H2B-1B and ZAG-showed potential interaction with PrP, specifically in rpAD cases. H2B-1B has already been studied in $\mathrm{AD}$ cases in relation to damage to DNA and cell cycle activation, and it is critical for rapid p53-mediated cell cycle inhibition, caspase-3 activation, and for inducing the phosphorylation of histone leading to cell death [26]. ZAG is a $40 \mathrm{kDa}$ glycoprotein; one study shows that the relevance of ZAG in dementia is the differentially regulated cerebrospinal fluid protein in frontotemporal dementia patients [27]. It is interesting to note that one protein, myelin $\mathrm{P} 2$, was isolated as a binding partner with the PrP isoform in spAD samples, suggesting a possible link with spAD cases.

Furthermore, our data set demonstrates that three proteins, ribonuclease UK114, fructosebisphosphate aldolase A, and lysozyme C, specifically interact with $\mathrm{PrP}$ isolated from spAD and controls. Fructose-bisphosphate aldolase A is known as binding partner of the cellular form of $\operatorname{PrP}$ [28] and has also been reported to be significantly upregulated in the cerebrospinal fluid of SCJD (human prion disease), but not in AD [29]. There was no regulatory response observed in the brains of CJD and $\mathrm{AD}$ cases [29]. The involvement of fructose-bisphosphate aldolase A in CJD and rpAD cases demonstrates a similarly rapidly progressive mechanism in both diseases.

Our interactomic approach includes a list of known and novel PrP-interacting proteins. Several proteins identified in this study are unique in relation to $\mathrm{AD}$ 
and its various forms, and are crucial for various cellular pathways. Determining this translational aspect of disease progression is of importance in further understanding the slow or fast progression of $\mathrm{AD}$.

\section{ACKNOWLEDGMENTS}

This work was supported by a grant from Helmholtz-Alberta Initiative-Infectious Diseases Research (HAI-IDR) and APRI-Human prionsdistinguishing sporadic from familial forms via structure and function as well as from the DZNE clinical project (Helmholtz). The study was performed within the recently established Clinical Dementia Center at the University Medical Hospital Göttingen and was partly supported by grants from the EU Joint Program- Neurodegenerative Disease Research (JPND - DEMTEST (Biomarker based diagnosis of rapid progressive dementias-optimization of diagnostic protocols, 01ED1201A).

Authors' disclosures available online (http://j-alz. com/manuscript-disclosures/17-0237r1).

\section{SUPPLEMENTARY MATERIAL}

The supplementary material is available in the electronic version of this article: http://dx.doi.org/ 10.3233/JAD-170237.

\section{REFERENCES}

[1] Mount C, Downton C (2006) Alzheimer disease: Progress or profit? Nat Med 12, 780-784.

[2] Burns A, Iliffe S (2009) Alzheimer's disease. BMJ 338, b158.

[3] Schellenberg GD, Montine TJ (2012) The genetics and neuropathology of Alzheimer's disease. Acta Neuropathol 124, 305-323.

[4] Selkoe DJ (2011) Alzheimer's disease. Cold Spring Harb Perspect Biol 3, pii: a004457.

[5] Schmidt C, Redyk K, Meissner B, Krack L, von AN, Roeber S, Kretzschmar H, Zerr I (2010) Clinical features of rapidly progressive Alzheimer's disease. Dement Geriatr Cogn Disord 29, 371-378.

[6] Schmidt C, Haik S, Satoh K, Rabano A, Martinez-Martin P, Roeber S, Brandel JP, Calero-Lara M, de Pedro-Cuesta J, Laplanche JL, Hauw JJ, Kretzschmar H, Zerr I (2012) Rapidly progressive Alzheimer's disease: A multicenter update. J Alzheimers Dis 30, 751-756.

[7] Cohen ML, Kim C, Haldiman T, ElHag M, Mehndiratta P, Pichet T, Lissemore F, Shea M, Cohen Y, Chen W, Blevins J, Appleby BS, Surewicz K, Surewicz WK, Sajatovic M, Tatsuoka C, Zhang S, Mayo P, Butkiewicz M, Haines JL, Lerner AJ, Safar JG (2015) Rapidly progressive Alzheimer's disease features distinct structures of amyloid-beta. Brain 138, 1009-1022.

[8] Zafar S, Younas N, Correia S, Shafiq M, Tahir W, Schmitz M, Ferrer I, Andreoletti O, Zerr I (2017) Strain-specific altered regulatory response of Rab7a and tau in CreutzfeldtJakob disease and Alzheimer's disease. Mol Neurobiol 54, 697-709.

[9] Chitravas N, Jung RS, Kofskey DM, Blevins JE, Gambetti P, Leigh RJ, Cohen ML (2011) Treatable neurological disorders misdiagnosed as Creutzfeldt-Jakob disease. Ann Neurol 70, 437-444.

[10] Murray ME, Graff-Radford NR, Ross OA, Petersen RC, Duara R, Dickson DW (2011) Neuropathologically defined subtypes of Alzheimer's disease with distinct clinical characteristics: A retrospective study. Lancet Neurol 10, 785-796.

[11] Hainfellner JA, Wanschitz J, Jellinger K, Liberski PP, Gullotta F, Budka H (1998) Coexistence of Alzheimer-type neuropathology in Creutzfeldt-Jakob disease. Acta Neuropathol 96, 116-122.

[12] Voigtlander T, Kloppel S, Birner P, Jarius C, Flicker H, Verghese-Nikolakaki S, Sklaviadis T, Guentchev M, Budka H (2001) Marked increase of neuronal prion protein immunoreactivity in Alzheimer's disease and human prion diseases. Acta Neuropathol 101, 417-423.

[13] Del BR, Scarlato M, Ghezzi S, Martinelli-Boneschi F, Fenoglio C, Galimberti G, Galbiati S, Virgilio R, Galimberti D, Ferrarese C, Scarpini E, Bresolin N, Comi GP (2006) Is M129V of PRNP gene associated with Alzheimer's disease? A case-control study and a meta-analysis. Neurobiol Aging 27, 770-770.

[14] Bertram L, McQueen MB, Mullin K, Blacker D, Tanzi RE (2007) Systematic meta-analyses of Alzheimer disease genetic association studies: The AlzGene database. Nat Genet 39, 17-23.

[15] Dermaut B, Croes EA, Rademakers R, Van den Broeck M, Cruts M, Hofman A, van Duijn CM, Van BC (2003) PRNP Val129 homozygosity increases risk for early-onset Alzheimer's disease. Ann Neurol 53, 409-412.

[16] Riemenschneider M, Klopp N, Xiang W, Wagenpfeil S, Vollmert C, Muller U, Forstl H, Illig T, Kretzschmar H, Kurz A (2004) Prion protein codon 129 polymorphism and risk of Alzheimer disease. Neurology 63, 364-366.

[17] Um JW, Strittmatter SM (2013) Amyloid-beta induced signaling by cellular prion protein and Fyn kinase in Alzheimer disease. Prion 7, 37-41.

[18] Kessels HW, Nguyen LN, Nabavi S, Malinow R (2010) The prion protein as a receptor for amyloid-beta. Nature $\mathbf{4 6 6}$, E3-E4.

[19] Dohler F, Sepulveda-Falla D, Krasemann S, Altmeppen H, Schluter H, Hildebrand D, Zerr I, Matschke J, Glatzel M (2014) High molecular mass assemblies of amyloid-beta oligomers bind prion protein in patients with Alzheimer's disease. Brain 137, 873-886.

[20] Kostylev MA, Kaufman AC, Nygaard HB, Patel P, Haas LT, Gunther EC, Vortmeyer A, Strittmatter SM (2015) Prion-protein-interacting amyloid-beta oligomers of high molecular weight are tightly correlated with memory impairment in multiple Alzheimer mouse models. J Biol Chem 290, 17415-17438.

[21] Grau-Rivera O, Gelpi E, Nos C, Gaig C, Ferrer I, Saiz A, Llado A, Molinuevo JL, Graus F, Sanchez-Valle R (2015) Clinicopathological correlations and concomitant pathologies in rapidly progressive dementia: A brain bank series. Neurodegener Dis 15, 350-360. 
[22] Robertson D, Savage K, Reis-Filho JS, Isacke CM (2008) Multiple immunofluorescence labelling of formalin-fixed paraffin-embedded (FFPE) tissue. BMC Cell Biol 9, 13.

[23] Keller A, Nesvizhskii AI, Kolker E, Aebersold R (2002) Empirical statistical model to estimate the accuracy of peptide identifications made by MS/MS and database search. Anal Chem 74, 5383-5392.

[24] Bonetta L (2010) Protein-protein interactions: Interactome under construction. Nature 468, 851-854.

[25] Falker C, Hartmann A, Guett I, Dohler F, Altmeppen H, Betzel C, Schubert R, Thurm D, Wegwitz F, Joshi P, Verderio C, Krasemann S, Glatzel M (2016) Exosomal cellular prion protein drives fibrillization of amyloid beta and counteracts amyloid beta-mediated neurotoxicity. J Neurochem 137 , 88100.

[26] Yu X, Caltagarone J, Smith MA, Bowser R (2005) DNA damage induces cdk2 protein levels and histone H2B phosphorylation in SH-SY5Y neuroblastoma cells. J Alzheimers Dis, 7-21.

[27] Hansson SF, Puchades M, Blennow K, Sjogren M, Davidsson P (2004) Validation of a prefractionation method followed by two-dimensional electrophoresis - Applied to cerebrospinal fluid proteins from frontotemporal dementia patients. Proteome Sci $\mathbf{2}, 7$.

[28] Zafar S, von AN, Oellerich M, Zerr I, Schulz-Schaeffer WJ, Armstrong VW, Asif AR (2011) Proteomics approach to identify the interacting partners of cellular prion protein and characterization of Rab7a interaction in neuronal cells. J Proteome Res 10, 3123-3135.

[29] Gawinecka J, Dieks J, Asif AR, Carimalo J, Heinemann U, Streich JH, Dihazi H, Schulz-Schaeffer W, Zerr I (2010) Codon 129 polymorphism specific cerebrospinal fluid proteome pattern in sporadic Creutzfeldt-Jakob disease and the implication of glycolytic enzymes in prion-induced pathology. J Proteome Res $9,5646-5657$.

[30] Medici S, Peana M, Nurchi VM, Zoroddu MA (2013) The involvement of amino acid side chains in shielding the nickel coordination site: An NMR study. Molecules 18, 1239612414.

[31] Roher AE, Maarouf CL, Sue LI, Hu Y, Wilson J, Beach TG (2009) Proteomics-derived cerebrospinal fluid markers of autopsy-confirmed Alzheimer's disease. Biomarkers 14, 493-501.

[32] Lee YJ, Goo JS, Kim JE, Nam SH, Hwang IS, Choi SI, Lee HR, Lee EP, Choi HW, Kim HS, Lee JH, Jung YJ, Kim HJ, Hwang DY (2011) Peroxiredoxin I regulates the component expression of gamma-secretase complex causing the Alzheimer's disease. Lab Anim Res 27, 293-299.

[33] Weinreb O, Bar-Am O, Amit T, Drigues N, Sagi Y, Youdim MB (2008) The neuroprotective effect of ladostigil against hydrogen peroxide-mediated cytotoxicity. Chem Biol Interact 175, 318-326.

[34] Cumming RC, Dargusch R, Fischer WH, Schubert D (2007) Increase in expression levels and resistance to sulfhydryl oxidation of peroxiredoxin isoforms in amyloid beta-resistant nerve cells. J Biol Chem 282, 30523-30534.

[35] Krapfenbauer K, Engidawork E, Cairns N, Fountoulakis M, Lubec G (2003) Aberrant expression of peroxiredoxin subtypes in neurodegenerative disorders. Brain Res $\mathbf{9 6 7}$, 152-160.

[36] Kim SH, Fountoulakis M, Cairns N, Lubec G (2001) Protein levels of human peroxiredoxin subtypes in brains of patients with Alzheimer's disease and Down syndrome. J Neural Transm Suppl 223-235.
[37] Chang RY, Etheridge N, Dodd PR, Nouwens AS (2014) Targeted quantitative analysis of synaptic proteins in Alzheimer's disease brain. Neurochem Int 75, 66-75.

[38] Crecelius A, Gotz A, Arzberger T, Frohlich T, Arnold GJ, Ferrer I, Kretzschmar HA (2008) Assessing quantitative post-mortem changes in the gray matter of the human frontal cortex proteome by 2-D DIGE. Proteomics $\mathbf{8}$, 1276-1291.

[39] Barker R, Ashby EL, Wellington D, Barrow VM, Palmer JC, Kehoe PG, Esiri MM, Love S (2014) Pathophysiology of white matter perfusion in Alzheimer's disease and vascular dementia. Brain 137, 1524-1532.

[40] Miners JS, Palmer JC, Love S (2016) Pathophysiology of hypoperfusion of the precuneus in early Alzheimer's disease. Brain Pathol 26, 533-541.

[41] Thomas T, Miners S, Love S (2015) Post-mortem assessment of hypoperfusion of cerebral cortex in Alzheimer's disease and vascular dementia. Brain 138, 1059-1069.

[42] Radovanovic I, Braun N, Giger OT, Mertz K, Miele G, Prinz M, Navarro B, Aguzzi A (2005) Truncated prion protein and Doppel are myelinotoxic in the absence of oligodendrocytic PrPC. J Neurosci 25, 4879-4888.

[43] Wilding BR, McGrath MJ, Bonne G, Mitchell CA (2014) FHL1 mutants that cause clinically distinct human myopathies form protein aggregates and impair myoblast differentiation. J Cell Sci 127, 2269-2281.

[44] Satoh J, Obayashi S, Misawa T, Sumiyoshi K, Oosumi K, Tabunoki H (2009) Protein microarray analysis identifies human cellular prion protein interactors. Neuropathol Appl Neurobiol 35, 16-35.

[45] Sheu KF, Clarke DD, Kim YT, Blass JP, Harding BJ, DeCicco J (1988) Studies of transketolase abnormality in Alzheimer's disease. Arch Neurol 45, 841-845.

[46] Paoletti F, Mocali A, Marchi M, Sorbi S, Piacentini S (1990) Occurrence of transketolase abnormalities in extracts of foreskin fibroblasts from patients with Alzheimer's disease. Biochem Biophys Res Commun 172, 396-401.

[47] Paoletti F, Mocali A (1991) Enhanced proteolytic activities in cultured fibroblasts of Alzheimer patients are revealed by peculiar transketolase alterations. J Neurol Sci 105, 211216.

[48] Lu'o'ng K, Nguyen LT (2011) Role of thiamine in Alzheimer's disease. Am J Alzheimers Dis Other Demen 26, 588-598.

[49] Mocali A, Della MN, Abete C, Mitidieri Costanza VA, Bavazzano A, Boddi V, Sanchez L, Dessi S, Pani A, Paoletti F (2014) Altered proteolysis in fibroblasts of Alzheimer patients with predictive implications for subjects at risk of disease. Int J Alzheimers Dis 2014, 520152.

[50] Lonsdale D (2015) Thiamine and magnesium deficiencies: Keys to disease. Med Hypotheses 84, 129-134.

[51] Selkoe DJ, Brown BA, Salazar FJ, Marotta CA (1981) Myelin basic protein in Alzheimer disease neuronal fractions and mammalian neurofilament preparations. Ann Neurol 10, 429-436.

[52] Hoos MD, Ahmed M, Smith SO, Van Nostrand WE (2009) Myelin basic protein binds to and inhibits the fibrillar assembly of Abeta42 in vitro. Biochemistry 48, 47204727.

[53] Zhan X, Jickling GC, Ander BP, Stamova B, Liu D, Kao PF, Zelin MA, Jin LW, DeCarli C, Sharp FR (2015) Myelin basic protein associates with AbetaPP, Abeta1-42, and amyloid plaques in cortex of Alzheimer's disease brain. JAlzheimers Dis 44, 1213-1229. 
[54] Chiarini A, Armato U, Liu D, Dal P, I (2016) Calciumsensing receptors of human neural cells play crucial roles in Alzheimer's disease. Front Physiol 7, 134.

[55] Tsutsui S, Hahn JN, Johnson TA, Ali Z, Jirik FR (2008) Absence of the cellular prion protein exacerbates and prolongs neuroinflammation in experimental autoimmune encephalomyelitis. Am J Pathol 173, 1029-1041.

[56] Patzig J, Jahn O, Tenzer S, Wichert SP, de MonasterioSchrader P, Rosfa S, Kuharev J, Yan K, Bormuth I, Bremer J, Aguzzi A, Orfaniotou F, Hesse D, Schwab MH, Mobius W, Nave KA, Werner HB (2011) Quantitative and integrative proteome analysis of peripheral nerve myelin identifies novel myelin proteins and candidate neuropathy loci. $\mathrm{J} \mathrm{Neu}$ rosci 31, 16369-16386.

[57] Bartzokis G (2011) Alzheimer's disease as homeostatic responses to age-related myelin breakdown. Neurobiol Aging 32, 1341-1371.

[58] Couttas TA, Kain N, Suchowerska AK, Quek LE, Turner N, Fath T, Garner B, Don AS (2016) Loss of ceramide synthase 2 activity, necessary for myelin biosynthesis, precedes tau pathology in the cortical pathogenesis of Alzheimer's disease. Neurobiol Aging 43, 89-100.

[59] Shearin H, Bessen RA (2014) Axonal and transynaptic spread of prions. $J$ Virol $\mathbf{8 8}, 8640-8655$.

[60] Takano M, Yamashita T, Nagano K, Otani M, Maekura K, Kamada H, Tsunoda S, Tsutsumi Y, Tomiyama T, Mori H, Matsuura K, Matsuyama S (2013) Proteomic analysis of the hippocampus in Alzheimer's disease model mice by using two-dimensional fluorescence difference in gel electrophoresis. Neurosci Lett 534, 85-89.

[61] Zahid S, Khan R, Oellerich M, Ahmed N, Asif AR (2014) Differential S-nitrosylation of proteins in Alzheimer's disease. Neuroscience 256, 126-136.

[62] Schmitz M, Zafar S, Silva CJ, Zerr I (2014) Behavioral abnormalities in prion protein knockout mice and the potential relevance of $\operatorname{PrP}(\mathrm{C})$ for the cytoskeleton. Prion 8, 381-386.

[63] Berman DE, Dall'Armi C, Voronov SV, McIntire LB, Zhang H, Moore AZ, Staniszewski A, Arancio O, Kim TW, Di PG (2008) Oligomeric amyloid-beta peptide disrupts phosphatidylinositol-4,5-bisphosphate metabolism. Nat Neurosci 11, 547-554.

[64] Zhu L, Zhong M, Elder GA, Sano M, Holtzman DM, Gandy S, Cardozo C, Haroutunian V, Robakis NK, Cai D (2015) Phospholipid dysregulation contributes to ApoE4-associated cognitive deficits in Alzheimer's disease pathogenesis. Proc Natl Acad Sci U S A 112, 11965-11970.

[65] McIntire LB, Lee KI, Chang-Ileto B, Di PG, Kim TW (2014) Screening assay for small-molecule inhibitors of synaptojanin 1, a synaptic phosphoinositide phosphatase. J Biomol Screen 19, 585-594.

[66] Martin SB, Dowling AL, Lianekhammy J, Lott IT, Doran E, Murphy MP, Beckett TL, Schmitt FA, Head E (2014) Synaptophysin and synaptojanin-1 in Down syndrome are differentially affected by Alzheimer's disease. J Alzheimers Dis 42, 767-775.

[67] Zampieri M, Legname G, Segre D, Altafini C (2011) A system-level approach for deciphering the transcriptional response to prion infection. Bioinformatics 27, 3407-3414.
[68] Reddy PH, Mani G, Park BS, Jacques J, Murdoch G, Whetsell W Jr, Kaye J, Manczak M (2005) Differential loss of synaptic proteins in Alzheimer's disease: Implications for synaptic dysfunction. J Alzheimers Dis 7, 103-117.

[69] Arnold SE, Louneva N, Cao K, Wang LS, Han LY, Wolk DA, Negash S, Leurgans SE, Schneider JA, Buchman AS, Wilson RS, Bennett DA (2013) Cellular, synaptic, and biochemical features of resilient cognition in Alzheimer's disease. Neurobiol Aging 34, 157-168.

[70] Counts SE, Alldred MJ, Che S, Ginsberg SD, Mufson EJ (2014) Synaptic gene dysregulation within hippocampal CA1 pyramidal neurons in mild cognitive impairment. $\mathrm{Neu}$ ropharmacology 79, 172-179.

[71] Hoos MD, Richardson BM, Foster MW, Everhart A, Thompson JW, Moseley MA, Colton CA (2013) Longitudinal study of differential protein expression in an Alzheimer's mouse model lacking inducible nitric oxide synthase. J Proteome Res 12, 4462-4477.

[72] Tribouillard-Tanvier D, Carroll JA, Moore RA, Striebel JF, Chesebro B (2012) Role of cyclophilin A from brains of prion-infected mice in stimulation of cytokine release by microglia and astroglia in vitro. $J$ Biol Chem 287, 46284639.

[73] Jang B, Kim E, Choi JK, Jin JK, Kim JI, Ishigami A, Maruyama N, Carp RI, Kim YS, Choi EK (2008) Accumulation of citrullinated proteins by up-regulated peptidylarginine deiminase 2 in brains of scrapie-infected mice: A possible role in pathogenesis. Am J Pathol 173, 11291142.

[74] Sultana R, Boyd-Kimball D, Cai J, Pierce WM, Klein JB, Merchant M, Butterfield DA (2007) Proteomics analysis of the Alzheimer's disease hippocampal proteome. J Alzheimers Dis 11, 153-164.

[75] Zafar S, Asif AR, Ramljak S, Tahir W, Schmitz M, Zerr I (2014) Anchorless 23-230 PrPC interactomics for elucidation of PrPC protective role. Mol Neurobiol 49, 1385-1399.

[76] Helmfors L, Boman A, Civitelli L, Nath S, Sandin L, Janefjord C, McCann H, Zetterberg H, Blennow K, Halliday G, Brorsson AC, Kagedal K (2015) Protective properties of lysozyme on beta-amyloid pathology: Implications for Alzheimer disease. Neurobiol Dis 83, 122-133.

[77] Nystrom S, Hammarstrom P (2015) Generic amyloidogenicity of mammalian prion proteins from species susceptible and resistant to prions. Sci Rep 5, 10101.

[78] Ferrer I, Rivera R, Blanco R, Marti E (1999) Expression of proteins linked to exocytosis and neurotransmission in patients with Creutzfeldt-Jakob disease. Neurobiol Dis $\mathbf{6}$, 92-100.

[79] Osborne C, West E, Nolan W, McHale-Owen H, Williams A, Bate C (2016) Glimepiride protects neurons against amyloid-beta-induced synapse damage. Neuropharmacology 101, 225-236.

[80] Williams RS, Bate C (2016) An in vitro model for synaptic loss in neurodegenerative diseases suggests a neuroprotective role for valproic acid via inhibition of cPLA2 dependent signaling. Neuropharmacology 101, 566-575.

[81] Spielhaupter C, Schatzl HM (2001) PrPC directly interacts with proteins involved in signaling pathways. J Biol Chem 276, 44604-44612. 